\title{
The Senior Leader as Both a Strategist and Technical Specialist
}

\author{
By Eric B. Dent
}

In the past, it was not uncommon for a major league baseball manager to also be one of the players of the team. Today, these positions are so specialized that this practice no longer occurs. However, modern organizations are increasingly moving in the direction of the old baseball team model, having senior leaders also "playing” in operational roles. I refer to this phenomenon as the “John McGraw duality,” in honor of a player/manager, who for eight seasons, managed a team to a World Series championship and also played at a level where he led the league in onbase-percentage three times. John McGraw (1873-1934) had a skill set that allowed him to be a very successful leader. His team depended on him for his individual expertise on the field and at the plate.

\section{The New Role of Senior Leader - Strategist and Technical Specialist}

As we plunge further into the twenty-first century, the role of senior leader ${ }^{1}$ continues to change and evolve. The litany of trends impacting organizations and their leaders is now familiar globalization (Friedman, 2005), technology expansion, organizational streamlining, increasing knowledge work, the significance of design playing a larger role in products and services (Pink, 2005), aging workforces and populations, multi-cultural workforces, and increasing complexity (Vaill, 1989). Of particular importance in this chapter are the trends of organizational streamlining, increasing knowledge work, design issues playing a larger role in products and services, and increasing complexity.

\footnotetext{
1 The term "senior leader" is used throughout this chapter to mean people at the top, or near the top, of privatesector, public-sector, and non-profit organizations. These people would typically have titles such as CEO, president, executive director, senior executive service (SES) member, vice president, COO, and the like.
} 
Because of these trends, organizations no longer have sizeable, if any, staff supporting the senior leader in areas such as strategic planning. In knowledge organizations, the senior leader is more likely to be able to relate directly to the work conducted by employees lower in the organization. When design and form play a larger role in the organization's products and/or services, the senior leader is more likely to have a "feel" for the product or service as opposed to a more utilitarian or science-driven product or service. For example, senior leaders have developed ideas about aesthetic spaces for customers, about "lifestyle" vacations that involve doing charitable work, and about bringing design elements to products sold at discount stores such as Target and Kmart. Finally, greater complexity demands that the senior leader be able to integrate and synthesize information about the organization, perhaps, in a way that no one else can.

Leaders today have challenging roles. The expectations and responsibilities of their position are not only demanding, but changing as well. These changes rarely reduce actions, competencies, or accountabilities of senior leaders; instead, they nearly always add to expectations and responsibilities. Heavy demands increase stress and anxiety and an overwhelming feeling that a leader is constantly battling to increase organizational performance. In fact, the responsibilities have become so significant that some have called for a sharing of all responsibilities between two people at the top of an organization (O’Toole, Galbraith, \& Lawler III, 2002; Pearce \& Barkus, 2004).

All of this suggests that the senior leader's role may be quite different than it was, say, twenty years ago. One way in which the role has changed is that senior leaders no longer provide only 
leadership and managerial oversight to an organization. Increasingly, senior leaders are also the key contributor in some individual or technical way.

Whiteley (2001) and others (Miller, 1999) use the term Renaissance Manager to connote the leader who also has technical responsibilities. He finds this notion so pervasive that he writes, "the dichotomy between a leader and a technician has long been something of an office joke. But these days it is not very funny. High rates of innovation and rapidly changing markets demand that the two sides become one” (48). In a modern working environment it has become increasingly prevalent for senior leaders to have technical and leadership responsibilities.

\section{New Role Examples}

What forms do these combinations of leader and technical work take? In my consulting practice, which is now largely executive coaching, I get firsthand, in-depth exposure to these combinations and their challenges. A senior vice president of mergers and acquisitions at a Fortune 500 company has a sizeable organization to lead, but is also held accountable for what mergers and acquisitions the company accomplished. He is the primary dealmaker for the company. It is his networking, his relationship with investment bankers, and his business acumen upon which the organization depends. None of this work can be delegated through his managerial structure. Likewise, I have worked with a high-ranking general in the Air Force, who managed hundreds of people, and was also the financial expert on certain budget matters. In health-related organizations, it is common to find that the executive director is also the organization's expert in an area such as 
epidemiology. It is also typical in large law firms to find that the senior leader is also considered to be the firm's best litigator or dealmaker.

The ability to combine technical expertise and business leadership is at the heart of some of today's most successful organizations. Dell is a good example of a corporation that makes explicit the requirement that leaders have this combination and the company attributes much of its success to it. Other examples include General Electric, United Parcel Services (UPS), and Bausch \& Lomb. All of these organizations are very successful and have one common view when it comes to technical expertise. They understand that the most appropriate people to fill the leadership positions are those who have dual knowledge of the technical and leadership aspects of the firm (Whiteley, 2001).

Based on my experience and observation, I contend that the number of senior leaders who have significant non-leadership expertise that their organizations depend on is surprisingly high. When I first shared this observation with senior leaders and academic colleagues, some were skeptical of its pervasiveness. But as we considered case after case, we found that it is more common than exceptional. A large number of examples arose from a radio talk show I co-hosted for a year and a half called LeaderTalk. Every week we interviewed CEOs such as Carly Fiorina, then at Hewlett Packard, Paul Diaz at Kindred Healthcare, and senior leaders of other organizations both large and small. Nearly every senior leader said, "Even though I'm the CEO, I'm also my company's expert on total battlefield weapons systems...." or by the CEO of a large federal contractor, "I'm our company's expert on the bid and proposal process" or "I still have 
more expertise on how to market our products than anyone in the company." Some of these comments may be bravado, but there seems to be more to it than that.

In the section below, Who Will Make the Next Breakthrough?, I take up the question of what types of organizations require this dual combination of leader.

\section{The Challenges of Being a Strategist and Technical Specialist}

In my executive coaching work, I find that I am almost always asked a question along the lines

of,

"I am asked to lead and manage a large organization, but I am also my organization's expert on [...]. My work as the expert is more visible, and frankly, what the organization holds me more accountable for. I want to manage my organization effectively, but any extra time I spend doing that takes away from my time in my area of expertise. What is the least amount of time I can devote to effectively lead and manage my organization so that I can spend as much time as possible in my specialty area?”

Interviews for this study provided a richer feel for the challenge posed by two sets of competencies. A senior leader in the U.S. Department of Agriculture comments, APublic service managers like myself need the tools to be both an expert and a manager. My individual expertise, as a senior risk analyst is required for long-term research and development. As a manager, I am inundated with managerial tasks, which, while important, take time away from my individual expertise, which is more highly valued by USDA. I have sought insight from consultants, the 
literature and from fellow managers to help with these conflicting tasks. Few seem to be able to help because everyone is focused on one side or the other."

A second quote speaks to the challenge and tension implicit in today's senior leadership. "As a senior manager within a Department of Defense corporate university, the toughest challenge I face in my role is balancing my time and energy between leading people and change, with fulfilling my role as the organization's expert in learning assessment, evaluation, and performance measurement. My dual role as an organizational leader and technical expert creates a kind of cognitive dissonance for me in that there is a prevailing belief that management success is not based on domain specific technical expertise, rather is measured by success in demonstrating leadership skills and managing organizational change.”

I feel this tension very directly myself. As I sit here writing this chapter, I serve as the Dean of a business school and as a professor of management. For the first time in my career, I was unable to meet the deadline for my work on this chapter as a professor because the managerial and leadership responsibilities of being dean have been all-consuming in the past few months. Thank goodness for extensions! Senior leaders of many organizations today are hoping for extensions (and mostly not getting them).

As noted by the USDA senior leader above, he and his counterparts are now wearing multiple hats and wondering how to be effective in each role. Their education did not prepare them for this role and they are not finding assistance on how to manage this balancing act. They ask a question that doesn't typically come up in business schools or with management consultants. 
What is the minimum I can do in my managerial role and still have some assurance that the job is done effectively? The following section summarizes what an inquirer will find if she looks for answers in college business textbooks.

\section{What Textbooks Teach}

Business textbooks convey the conventional wisdom of the field. At the same time, they have been criticized for being behind the times, only progressing when concepts are considered “received truth” (Dent \& Goldberg, 1999). The received truth on this subject is that managers increasingly dispense with expert roles (which the textbooks call technical skills) as they climb the ladder. As they reach the top rung, they engage entirely in strategic work, delegating any technical tasks to subordinates. The technical expertise is seen as residing in the bench scientist or the manufacturing line foreman. This view is nicely encompassed in this textbook passage.

Upper managers spend most of their time planning and leading because they make decisions about the overall performance and direction of the organization. Therefore, they are usually involved in the development of goals and strategies to achieve those goals. Conceptual and interpersonal skills are especially important.... Middle managers are those managers who receive broad statements of strategy and policy from upper-level managers and develop specific objectives and plans. They spend a large portion of their time in planning and organizing activities. Conceptual and technical skills underlie these activities.... Lower or first-line managers are those concerned with the direct production of items or delivery of service. These actions require leading and controlling. Because 
first-line managers train and monitor the performance of their subordinates, technical skills are especially important. (Gatewood, Taylor, \& Ferrell, 1995, 17).

Statements such as this are typically accompanied by a visual depiction of a pyramid and an inverted pyramid as illustrated in Figure 1. The message of these diagrams is that as someone is promoted, the organization depends less on her technical expertise and more on her strategic expertise. This message is in contrast to the reports of senior leaders who state that the organization continues to depend on them for technical expertise in some area, and that dependence may increase rather than decrease. It seems to be the case that as someone moves up the managerial ladder she is simultaneously developing an individual expertise that is also increasingly valuable to the organization. As a result, managerial and technical expertise are hypothesized to be positively correlated instead of displaying an inverse relationship, the viewpoint of modern college textbooks. 


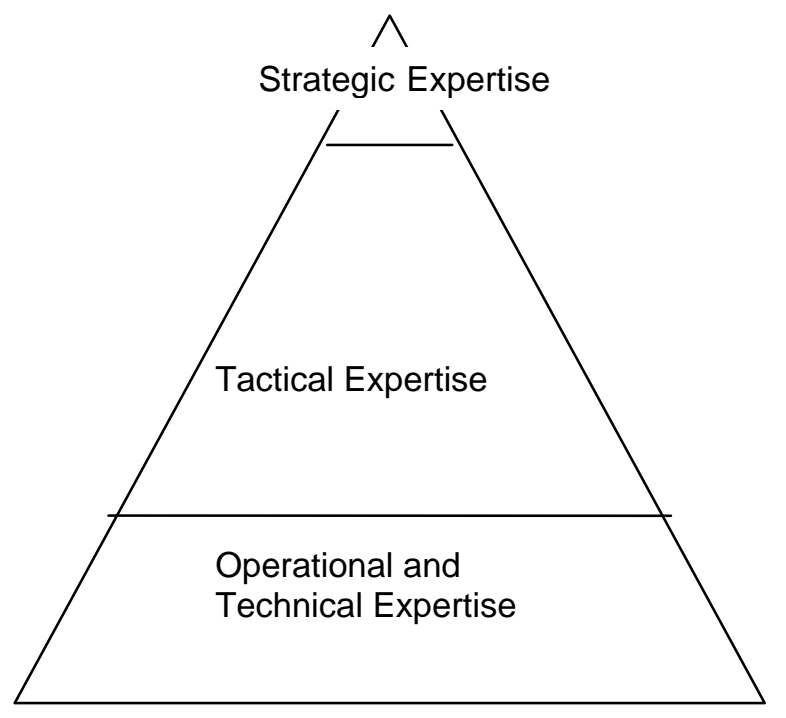

Lower-level Manager

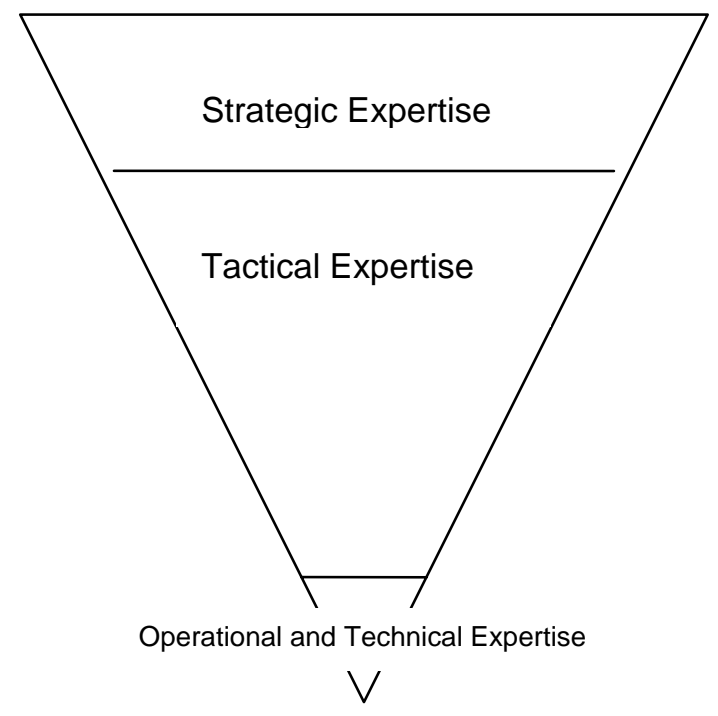

Senior-level Manager

Figure 1. Role differences between lower-level and senior-level Managers.

\section{The So-called "Dual Ladder"}

Another way that organizations have attempted to address the issue of high-level technical expertise is through the practice of dual ladders for career growth. The idea of dual ladders recognizes that the organization depends on high-level technical or individual contributions, equivalent in status to senior managerial roles. It is acknowledgment that some people should progress in their careers without having to become managers. In practice, though, the dual ladder concept has not been very successful. Most organizations that have tried to implement dual ladders have provided for disproportionately small numbers of high-level technical positions. In the United States’ federal government, for example, there are twenty times as many senior 
executive service (SES) personnel as there are "supergrades," the term used for technical positions at the same rank as SES. The situation is the same at corporations such as IBM. The high-level technical positions make the most sense in scientific areas and with individuals with only minimal managerial competencies. The vast majority of situations where high-level technical or individual expertise is required are not like this. They involve expertise in marketing, process, creativity, deal making, legal matters, and so forth. Many of the individuals in high-level positions with significant technical expertise are in managerial roles by choice.

The recognition of the senior leader role having two major elements has interesting implications. It provides an explanation for why the dual ladder concept has not worked in broad application. Secondly, it offers a reconceptualization of senior leadership. Perhaps the most important distinction is not between "technical” and “managerial” but between "specialist manager” and “general manager.” Right now, individual expertise is often not formally recognized in titles and other explicit forms. Academia may be the exception and the model to follow in this case because it is common to see organizationally-sanctioned expertise listed such as "Dean, School of Business and Professor, Management.” Organizations might be more effective if they made more explicit these "specialist manager” areas of expertise.

If additional research confirms the premise of this chapter, textbook authors will need to make substantive changes in how they have traditionally conceptualized top leadership behaviors. Management faculty will also need to redesign how they are teaching executive leadership in universities. Since textbooks are often lagging “indicators” of organizational practice, let’s look 
now at the cutting-edge of academia, the journal articles that contain the latest thinking and work of faculty researchers.

\section{What Academics and Consultants Encourage}

A common critique of academics and consultants is that they are too specialized, too disciplinespecific. It is no secret that marketing faculty believe marketing to be the most critical function for organizations, strategy faculty believe strategy to be the most critical function for organizations, and so on. Consultants, likewise, are known for having their particular tools and techniques and wanting to apply them regardless of the situation. It goes back to that familiar adage, when all you have is a hammer; everything begins to look like a nail. Consequently, the consulting profession and academia are not structured in a way that would cause a member of either to entertain the question, "What is the least amount of time I can devote to effectively lead and manage my organization so that I can spend as much time as possible in my specialty area?” Academics are working hard to develop breakthroughs in their disciplines that become beneficial to organizations (such as Michael Porter’s five underlying forces for competitive advantage - rivalry, supplier power, barriers to entry, threat of substitutes, and buyer power). Likewise, consultants are developing tools such as balanced scorecard, total quality management, and reengineering.

The result is what I refer to as the "piling on effect." No expert ever finds that a leader's activity in the expert's area can be reduced. On the contrary, ever increasing nuanced activity in that area is called for. Articles by professors and consultants frequently recommend additional critical factors that a senior leader must master to truly be effective. Senior leaders are told they must 
think strategically (Ornoff, 2002); that they must develop “relational equity” to do their jobs effectively (Sawhney \& Zabin, 2002); that performance appraisals are “critical to success” (Camardella, 2003); that a certain degree of toughness and resilience is "critical to success" (Alexander, 2005); that leaders must have generational awareness (Salopek, 2006); that leader-member interactions are most important (Campbell, White, \& Johnson, 2003). Other articles suggest that the "critical” success factor is empowerment or financial acumen or systems thinking or vision or image management. As with the trends impacting organizations and senior leaders, this list also goes on and on.

I have systematically analyzed the literature and determined that there is no extant research that attempts to answer the question raised by the leaders above. No one has published research on what the minimum approach to the managerial role can be and still have some assurance that the job is performed effectively. In one of the only articles that come close to discussing this topic, Llewellyn (2001) coins the term “two-way windows” to describe doctors who have both managerial and clinical responsibilities. Her research further suggests that "all public bureaucracies now involve complex mediation between professional [work] and managerial [work].” An additional implication of her work is that this "specialist manager” role may be what is desirable and required. The question remains, how much time should someone holding this role spend on the specialty and how much on management? How can the management activity be performed most efficiently and effectively? Llewellyn makes the argument that this is a desirable role for organizations because the senior leader who is also an individual contributor is uniquely situated to understand the macro and micro, the technical and managerial, and the 
back-office and front-line dynamics and contexts. It is as though these people are looking through a window two different ways along a variety of perspectives (Llewellyn, 2001).

The management and organizational literature currently reflects a situation that does not appear to match reality. The literature suggests that the higher an individual rises in the organization, the less technical expertise is required. The literature assumes that this technical expertise is needed in the lower levels of the organization and that the top levels require more tactical and strategic skills. Moreover, the senior leader is advised by professors and consultants that the managerial responsibilities require an increasingly sophisticated and critical set of skills such as developing relational equity and developing generational awareness.

\section{Who Will Make the Next Breakthrough?}

Another way to think about the topic of this chapter is to ask the question, "who will be primarily responsible for the next product/service advancement in the organization?” During the industrial era, scientists, engineers, and technicians were expected to develop the breakthrough products and services. Consequently, the transistor, post-it notes, anti-lock braking systems and other similar inventions were all developed by people in the lower levels of the organization. Even in that era there would be some exceptions such as Thomas Edison, who, although CEO of Edison General Electric Company, continued to be an inventor. Another example is Henry Ford who pioneered the assembly line, a breakthrough for all manufacturing.

In today's era of information, services, and design, a senior leader often contributes the next breakthrough. Although it is unlikely that one person could understand all of the technology 
necessary to launch a new automotive company, the shift to a knowledge-based organization means that it is possible for the CEO to have all of the "technology" about an information-based product or service in her head. It is also possible for the senior leader to have a breakthrough innovation in design or form. Examples of these contributions abound. Like Thomas Edison, Bill Gates may be atypical. He is well-known for his early individual contributions in operating systems. Now as a senior leader of a more than forty billion dollar corporation, he still provides substantial technical expertise in the areas of "public key certificates" (combinations of digital signatures and identifying information such as a person's name, address and social security number) and rights-management systems to limit who forwards or opens email messages, reducing the risk of data loss.

A more typical example, although with exceptional achievement, is Michael Dell. He and other senior leaders at the Dell Corporation do not have patents for inventions that make better Dell products. They have discovered ways of making manufacturing and distribution processes more efficient. Although recently having lost its edge, Dell built its worldwide reputation for excellence largely on Michael Dell’s ideas. Another noteworthy example is Jeffrey Bezos at Amazon Corporation. Bezos developed a number of ideas that were new to the book selling industry, including many that were new to business itself. Bezos pioneered the concept of "get big fast.” His strategy was for Amazon to become the largest online retailer in the book-selling industry (later branching out to other industries) even if it meant accumulating unprecedented losses along the way. During the dot-com era, Wall Street applauded this strategy, vaulting Amazon's market value to stratospheric levels. When the bubble burst, Amazon’s price also fell significantly, yet Bezos persevered with the strategy. Years later, his breakthrough has been 
vindicated. He was also largely responsible for other innovations at Amazon including inventory and distribution methods. In addition, Amazon was the first company to popularize features that are now common to many organizations such as customer wish lists (which can even be shared with friends and relatives similar to a bridal registry), online product reviews by non-experts (i.e. other customers), and analytics (a technology that is a more traditional break through - an important exception that will be discussed below). Analytics have allowed Amazon to suggest books to regular customers with an accuracy that is often shocking to them.

Another great example is Pierre Omidyar (founder and chairman) and Meg Whitman (President and CEO) of eBay, Incorporated. The main concept for the corporation, developed by these senior leaders, is to develop a "community, built on commerce, sustained by trust.” EBay was the first business to develop a community of commerce among people with no existing relationship. Another of eBay's guiding principles is equal access to information and opportunities. Omidyar and Whitman pioneered a system whereby buyers and sellers in a transaction provide input to a public database that tracks the trustworthiness of both parties. EBay has found that the community they have developed has forged such tight bonds that the community has been able to exert power over other innovations by the company. When eBay attempted to enact policies that the community believed to be inconsistent with the principles, norms, and culture of the community, the company was forced to bring its policies back into alignment with the community.

In A Whole New Mind, Daniel Pink has categorized trends that demonstrate the increasing significance of right-brain thinking to executive and other work. He suggests that current and 
future leaders will have proficiency with the six senses of Design, Story, Symphony, Empathy, Play, and Meaning. An example in the area of Play is a senior leader in the U.S. Army who "in a flash of right-brain inspiration (Pink, 2005, 182) concluded that that Army needed to change the way it was trying to recruit new soldiers from television ads and person-to-person persuasion to the use of a video game that provided a virtual experience of what it was like to be in the Army. The resulting product, America's Army, now has over two million registered users and is a breakthrough in how it takes players through basic training to become Green Berets, if they are successful along the way.

It is likely that most of the breakthroughs the reader can think of in the past ten years have come from senior leaders rather than scientists, researchers, or engineers ${ }^{2}$. Examples would include: Enterprise Rental Cars “We’ll pick you up“ strategy; Priceline‘s "Name your own price” strategy; the open architecture software idea as well as the strategy of making an operating system available free, as Linux has done; Banks and other lenders offering interest-only payments on home mortgages; and, grocery stores and other retailers providing self checkout. These are all well-known, dramatic examples, but think of some of the local organizations in your community for which this is also the case. Such small-business examples in my community include a woman who developed the idea of an online marketplace for matching truckers and their trips with customers who need products moved, a restaurateur who has created a dining experience that embodies and preserves the history of the community, and two sister

2 Obvious exceptions will not be discussed here. These generally require extremely specialized technical knowledge such as new pharmaceuticals, mobile phone technology breakthroughs, or trans-fat free food formulations. 
entrepreneurs who have combined medical home health care with spiritual and faith development.

Although I have made the case that the next breakthrough idea is likely to come from a senior leader, there is one powerful trend that serves as a counter example and merits attention here. Even in this case, the breakthrough is probably a combination of a technologist(s) together with the senior leader who has the vision for the application of the technology. As noted above, many regular customers of Amazon have had the eerie experience of having Amazon suggest a book to them and then discover that they absolutely love the book. How could some software running on the web be so good at predicting a reader's likes and dislikes based on a seemingly small amount of data? The answer is analytics (Davenport \& Harris, 2007). Analytics is the application of sophisticated information systems and rigorous analysis to the strategic functions of an organization. The airline industry was the first large-scale implementation of analytics when American Airlines began to identify reasonably regular patterns of ticket purchases. They realized that they could increase their overall revenues by decreasing the prices of tickets purchased at one point in time, but increasing the price of a ticket purchased at a later time. A crude example of analytics is a coast-to-coast flight that can be purchased several weeks in advance for $\$ 250$. If the flights that day begin to fill, the airline will start to increase the price of future tickets. The airlines know it is likely there will be last-minute flyers that absolutely need to fly at that time and will be willing to pay $\$ 1,500$ or $\$ 2,000$ to be on a particular flight. Likewise, an airline seat is the ultimate "perishable” commodity, so airlines achieve more revenue on a heavily-discounted seat than they do on an empty one. 
In recent years, analytic algorithms have become far more sophisticated, cheaper to implement, and more broadly used. As a baseball fan, I was an early reader of The Bill James Baseball Abstract (1977), the first sophisticated application of analytics to the performance of major league baseball players. This work has revolutionized the sport in the selection of athletes for the major league team and in the strategy during the game. James' work suggested, for example, that managers should value "Runs Created," which has greater predictive ability to the actual number of runs a team will score based on a given player's contribution more than typical statistics in use such as Runs Batted In or Runs Scored. James' first version of “Runs Created” was to multiply Total Bases by Hits plus Walks and divide the outcome by Plate Appearances. Many teams now have proprietary approximations of this statistic. Netflix, the movie rental company, uses movie preference algorithms in the same way that Amazon pioneered book purchase suggestions. Because the average Netflix customer rents more movies than the average Amazon customer buys books, Netflix’s algorithm is so precise that a typical customer is more likely to be satisfied by a movie Netflix suggests than one a customer "thinks" she will like (Davenport \& Harris, 2007).

Analytics requires gathering data in new and innovative ways and settings. This arena is where the senior leader's breakthrough is likely to occur. When grocery items were first marked with a scan code, stores were much better able to track inventory and product loss. A senior leader realized that the product scanning process combined with a customer card scanning process provided incredibly valuable data about purchases at the individual level. Another, perhaps, surprising industry that has been revolutionized by analytics is gaming. When gamblers are dropping coins or tokens into slot machines, the gaming establishment gathers very little 
information about the customer's spending habits and preferences. If the gambler registers and obtains a gambling card that is inserted into a slot machine, the gaming establishment is now in possession of a tremendous amount of valuable data. Through the use of these analytics, Harrah's has learned that they can generate substantially more revenue. For example, if a smalltime gambler has lost \$200, she may become discouraged and stop playing. If a Harrah’s employee comes by at that time and says ”you look like you aren’t having a lucky streak. Here’s a \$20 food voucher. Why don’t you go have a nice meal and try your luck again.” One relatively inexpensive intervention at an opportune time results in Harrah's having a much more satisfied customer, and one who will continue to play rather than giving up (Atwood, 2007).

So, there is still a place for the technologist in product and service breakthrough innovations. In an increasing number of industries and situations, though, a senior leader plays a major or supporting rule in the innovation.

\section{What Should the Leader Do?}

Given the current state of affairs, what is a senior leader with technical responsibilities to do? What follows is necessarily preliminary and speculative given the current stage of research. Certainly, each senior leader has to decide how much time she needs to spend leading and managing in her organization. A senior leader who is the CEO of a major medical center may find that staying current in her research and clinical responsibilities may require small amounts of her time and imposes small relative amounts of pressure compared with the leadership and management demands of running the organization. A senior leader at America Online may find that there are far greater pressures on the side where he has responsibility for the overall content 
of the website, determination of what content to give away and what to charge for, and how to be seen as desirable in the face of "hipper”, more nimble competitors. Regardless of the situation 'the senior leader will need to satisfice because it will likely be impossible to provide sustained great performance in both the leadership and technical roles.

Certainly, senior leaders should learn and apply the classic prescriptions about time management and delegation (although, by definition, the technical aspects cannot or should not be delegated). More recent work has shown that, although senior leaders have a tendency to get involved in too many areas and spread themselves too thin, the most successful leaders have the ability to stay focused on only the most important goals and activities. This finding has surfaced in very popular works such as the advice to "stick to the knitting” (Peters \& Waterman, 1982) and the “hedgehog concept” (Collins, 2001). The latter has found that the most successful leaders have a limited number of strategic initiatives that they pursue, and that they can be ruthless in asserting the priority of these activities over all others. They have a "simple, crystalline concept that flows from deep understanding about the intersection” (Collins, 2001, 95) of what you can be the best in the world at, what drives your economic engine, and what you are deeply passionate about.

Another suggestion that may seem counterintuitive is to minimize the number of staff employees reporting to the senior leader. This strategy has been successfully employed at companies such as the ABB Group (formerly Asea Brown Bavari) and Visa International. At first glance, it might seem that the more staff reports a senior leader has, the more work she can delegate to others. However, there is a tradeoff with direct reports. Bright, energetic staff members are likely to generate an increasing amount of work that involves the senior leader, or at least requires that 
she monitor it. All of the effort the senior leader has to expend likely violates the hedgehog concept, taking his attention away from the limited set of critical functions.

There is a dearth of research in this area, so senior leaders with technical responsibilities are largely left to their own devices in figuring out how to allocate their time. In the final section, we will briefly consider what future research avenues should be pursued to begin providing answers to the question of this chapter.

\section{Future Research}

Although the question posed in this chapter may be novel, at the same time, if there were easy answers, someone would have offered them by now. Consequently, it will take a large number of studies from a multitude of perspectives to begin to surface actionable strategies for senior leaders. This area of scholarship poses all the issues associated with researching "leadership" plus some. One important approach will be to foster studies that attempt to discern how senior leaders allocate their time among leadership and technical roles. Mintzberg’s (1975) landmark studies following an approach like this revealed that a leader spends fewer than nine minutes on most interactions. His research also offered a reconceptualization of the leadership and managerial role. Performing time analyses would be a helpful approach (Wilber, 2000) in discovering how senior leaders are managing there dual responsibilities. This approach would also address questions such as whether the dual roles are woven seamlessly through a work day or whether they are segregated into chunks of time. 
Because much of the leader's work involves thinking, the time analysis is unlikely to reveal a senior leader's thoughts and where his mind travels in "down” time such as driving the car or working out in the fitness center. An interior approach would involve interviewing senior leaders about proportions of time, energy, and mental exertion devoted to different responsibilities. This information would be useful, but is often confounded by at least two issues, retrospective sensemaking (Weick, 1995) and "Satchmo’s Paradox" (Vaill, 1989). The former refers to the fact that although we each live nonlinear experiences filled with known and unknown motives at any given time, when asked about our experience, we will construct a story that is much more orderly, purposeful, and socially acceptable than what we actually lived. The latter is an allusion to Louis Armstrong's response to the question, what is jazz? He essentially replied that if you have to ask you won't ever get it. Armstrong was unable to explain to others something that he understood well. Other research suggests that an individual can perform work at a higher level than she can meaningfully explain to someone else (Jaques, 2002). People can adequately explain to others work done one level of cognitive ability below the highest level they themselves can perform, but they cannot explain what they do when they are utilizing their highest level thinking.

Putting these issues aside for the moment, another helpful set of data would be first-person accounts from dual leaders who are operating effectively and have a high degree of selfawareness to minimize retrospective sensemaking and Satchmo’s Paradox. Occasionally, someone comes along who has these abilities, and writes a book that transforms the field. Such an example would be Chester Barnard's The Functions of The Executive. As for baseball player/manager, John McGraw, he died in 1934, so he is not available to explain to us what he 
did that allowed him to bat .391 in one season and also coach a team to a world series championship in his player/manager career. His insights would have been helpful.

\section{Bibliography and Suggested Further Readings}

Alexander, J. R. (2005) From the president, Leadership in Action. 25(3), 2.

Atwood, C. L. (2007, February). Beating the odds in the business of gaming. Presented at the AACSB Dean’s Conference, Las Vegas, NV.

Barnard, C. I. (1938). The functions of the executive. Cambridge, MA: Harvard University Press.

Camardella, M. J. (2003). Effective management of the performance-appraisal process. Employment Relations Today. 30(1), 103-107.

Campbell, K. S., White, C. D., \& Johnson, D. E. (2003). Leader-member relations as a function of rapport management, The Journal of Business Communication. 40(3), 170+.

Collins, J. (2005) Good to great: Why some companies make the leap-- and others don't. New York: HarperBusiness.

Davenport, T. \& Harris, J. (2007) Competing on analytics. Cambridge, MA: Harvard Business School Press.

Dent, E. B. \& Goldberg, S. G. (1999). Challenging "resistance to change," Journal of Applied Behavioral Science, 35(1), 25-41.

Friedman, T. (2005). The world is flat : A brief history of the twenty-first century. New York: Farrar, Straus and Giroux.

Gatewood, R. D., Taylor, R.R., \& Ferrell, O.C. (1995). Management: Comprehension, analysis, and application. Chicago: Irwin Publishers. 
James, B. (1977). The Bill James baseball abstract. New York: Ballantine Books.

Jaques, E. (2002). Social power and the CEO: Leadership and trust in a sustainable free enterprise system. Westport, CT: Quorum Books.

Llewellyn, S. (2001). Two-way windows: Clinicians as medical managers, Organizational Studies, 22(4), 594-623.

Mintzberg, H. (1975). “The manager’s job: Folklore and fact.” Harvard Business Review. 53(4), 49-61.

Miller, C. (1999). The renaissance manager: Embracing the 3 dimensions of dynamic leadership. Supervision. 60(2), 6-8.

Ornoff, K. (2002). Developing strategic competencies: A starting point, Information Management Journal. 36(4), 57-62.

O’Toole, J., Galbraith, J., \& Lawler III, E.E. (2002). When two (or more) heads are better than one: The promise and pitfalls of shared leadership. California Management Review, 44(4), 65-79.

Pearce, C.L. \& Barkus, B. (2004). The future of leadership: Combining vertical and shared leadership to transform knowledge work. The Academy of Management Executive, 18(1), 47-57.

Peters, T. J., \& Waterman, R. H. (1982) In search of excellence: Lessons from America's bestrun companies. New York: Harper \& Row.

Pink, D. H. (2005). A whole new mind: Moving from the information age to the conceptual age. New York: Riverhead Books.

Salopek, J. J. (2006). Leadership for a new age, Training and Development. 60(6), 22-23. 
Sawhney, M. \& Zabin, J. (2002). Managing and measuring relational equity in the network economy, Academy of Marketing Science Journal. 30(4), 313+.

Vaill, P. B. (1989). Managing as a performing art: new ideas for a world of chaotic change. San Francisco: Jossey-Bass.

Weick, Karl E. (1995). Sensemaking in organizations. Thousand Oaks, CA: Sage Publications.

Whiteley, P. (2001). The renaissance manager. Director. London. 54(7), 48-51.

Wilber, K (2000). A brief history of everything ( $2^{\text {nd }}$ ed.). Boston: Shambhala. 